\title{
Mutation profile of non-small cell lung cancer revealed by next generation sequencing
}

Ya-Sian Chang 1,2,3,4, Siang-Jyun Tu², Yu-Chia Chen ${ }^{3}$, Ting-Yuan Liu ${ }^{3}$, Ya-Ting Lee ${ }^{1}$, Ju-Chen Yen ${ }^{1}$, Hsin-Yuan Fang ${ }^{5}$ and Jan-Gowth Chang $1,2,3,6,7^{*}$ (D)

\begin{abstract}
Background: Precision therapy for lung cancer requires comprehensive genomic analyses. Specific effects of targeted therapies have been reported in Asia populations, including Taiwanese, but genomic studies have rarely been performed in these populations.

Method: We enrolled 72 patients with non-small cell lung cancer, of whom 61 had adenocarcinoma, 10 had squamous cell carcinoma, and 1 had combined adenocarcinoma and squamous cell carcinoma. Whole-exome or targeted gene sequencing was performed. To identify trunk mutations, we performed whole-exome sequencing in two tumor regions in four patients.

Results: Nineteen known driver mutations in EGFR, PIK3CA, KRAS, CTNNB1, and MET were identified in 34 of the 72 tumors evaluated (47.22\%). A comparison with the Cancer Genome Atlas dataset showed that EGFR was mutated at a much higher frequency in our cohort than in Caucasians, whereas KRAS and TP53 mutations were found in only 5.56\% and $25 \%$ of our Taiwanese patients, respectively. We also identified new mutations in ARID1A, ARID2, CDK12, CHEK2, GNAS, H3F3A, KDM6A, KMT2C, NOTCH1, RB1, RBM10, RUNX1, SETD2, SF3B1, SMARCA4, THRAP3, TP53, and ZMYM2. Moreover, all ClinVar pathogenic variants were trunk mutations present in two regions of a tumor. RNA sequencing revealed that the trunk or branch genes were expressed at similar levels among different tumor regions.
\end{abstract}

Conclusions: We identified novel variants potentially associated with lung cancer tumorigenesis. The specific mutation pattern in Taiwanese patients with non-small cell lung cancer may influence targeted therapies.

Keywords: Non-small cell lung cancer, Whole-exome sequencing, Targeted gene sequencing, Trunk mutations

\section{Background}

Lung cancer is the leading cause of cancer-associated mortality worldwide. An estimated 2.09 million new lung cancer cases and 1.76 million lung cancer-associated mortalities were reported in the GLOBOCAN 2018 database [1]. Lung cancer can be divided into two broad categories according to histology: small-cell lung cancer and non-small-cell lung cancer (NSCLC). The latter comprises more than $80-85 \%$ of all lung cancers. NSCLC is

\footnotetext{
*Correspondence: d6781@mail.cmuh.org.tw

${ }^{1}$ Epigenome Research Center, China Medical University Hospital, 2 Yuh-Der Road, Taichung 404, Taiwan

Full list of author information is available at the end of the article
}

subdivided into adenocarcinoma (ADC; 60\%), squamous cell carcinoma (SqCC; 30-35\%), large cell carcinoma, and other rare tumors, including adenosquamous carcinoma [2]. Risk factors include tobacco consumption, genetic susceptibility, poor diet, air pollution and occupational exposures, such as asbestos, metals and mixed occupation exposures, silica, polycyclic aromatic hydrocarbons, and diesel exhaust fumes [3]. Tobacco smoking is the main risk factor for lung cancer; however, $10-15 \%$ of those diagnosed with lung cancer are never-smokers [4]. Epidemiologic studies reveal that the proportion of lung cancer in never-smokers is higher in East Asia [5]. Neversmoker East Asian females are diagnosed more often with $\mathrm{ADC}$, and these patients exhibit higher treatment original author(s) and the source, provide a link to the Creative Commons licence, and indicate if changes were made. The images or other third party material in this article are included in the article's Creative Commons licence, unless indicated otherwise in a credit line to the material. If material is not included in the article's Creative Commons licence and your intended use is not permitted by statutory regulation or exceeds the permitted use, you will need to obtain permission directly from the copyright holder. To view a copy of this licence, visit http://creativecommons.org/licenses/by/4.0/. The Creative Commons Public Domain Dedication waiver (http://creativeco mmons.org/publicdomain/zero/1.0/) applies to the data made available in this article, unless otherwise stated in a credit line to the data. 
response rates to epidermal growth factor receptor (EGFR) tyrosine kinase inhibitors [6]. Chest radiography, sputum cytology, and low-dose computed tomography (CT) have been used for lung cancer screening. Despite advances in genomic research and targeted therapies, leading to improvements in therapeutic strategies and the clinical outcomes of lung cancer patients [7], the overall 5-year survival rate of lung cancer remains very low (16.8\%) [8]. The prognosis of lung cancer remains poor because most patients are often diagnosed at an advanced stage.

Rapid advancements in next-generation sequencing technology and a better understanding of cancer biology have provided unprecedented opportunities to characterize the genome of human tumors including lung cancer. The Cancer Genome Atlas (TCGA) lung cancer working group has profiled and analyzed 230 ADC and $178 \mathrm{SqCC}$ specimens to identify molecular aberrations at the DNA, RNA, protein, and epigenetic levels $[9,10]$. In ADC, the most common mutations are TP53, KRAS, EGFR, NF1, BRAF, MET, and RIT. Pathway alterations in ADC are involved in RTK/RAS/RAF, mTOR, JAK-STAT, DNA repair, cell regulation, and epigenetic deregulation. Mutations in TP53, CDKN2A, PIK3CA, NFE2L2, KEAP1, CUL3, PTEN, NF1, NOTCH1, 2 and 3, DDR2, and EGFR genes are frequently observed in SqCC. Pathway alterations in SqCC involve squamous differentiation, the oxidative stress response, PIK3CA, DNA repair, cell cycle regulation, and epigenetic deregulation [11]. ADC and $\mathrm{SqCC}$ show genetic alterations or gene expression differences $[12,13]$. In ADC, the most common therapeutic targets are EGFR and BRAF mutations and $A L K$ and ROS1 rearrangements. Molecular genotyping is now routine in ADC. In SqCC, targeted agents are largely ineffective, and many targeted therapies are currently undergoing clinical trials [14].

To develop a more comprehensive genomic picture of NSCLC, we performed whole-exome sequencing (WES) or targeted gene sequencing (TGS) in 72 Taiwanese patients with NSCLC. In addition, we compared the results with the TCGA NSCLC dataset, which involves mainly Western populations. We also investigated the associations between genetic alterations and clinicopathological features.

\section{Materials and methods}

\section{Subjects and DNA extraction}

A total of 61 fresh-frozen and 11 formalin-fixed paraffin-embedded (FFPE) specimens were obtained from 72 Taiwanese patients with lung cancer who underwent surgical resection from May 2007 to April 2019 at the China Medical University Hospital. The 72 lung tumors comprised 61 ADCs, 10 SqCCs, and 1 combined ADC and
SqCC. DNA from frozen tissues and FFPE specimens was extracted using the QIAamp ${ }^{\circledR}$ DNA Micro Kit (Qiagen, Heidelberg, Germany) and QIAamp ${ }^{\circledR}$ DNA FFPE Tissue Kit (Qiagen) according to the manufacturer's instructions. The DNA concentration was quantified using the NanoDrop1000 spectrophotometer (Nanodrop Technologies, Wilmington, DE, USA) and a Qubit Fluorometer (Invitrogen, Carlsbad, CA, USA).

\section{TGS and data analysis}

TGS was performed using the Qiagen platform with a panel that included either 275 (cat. no. DHS-3501Z) or 72 genes (cat. no. DHS-005Z). DNA libraries were prepared using components from the QIAseq Targeted DNA Panel Kit (Qiagen) and QIAseq Targeted DNA Panel Human Lung Cancer Panel (Qiagen). Briefly, 80 ng DNA was enzymatically fragmented and end-repaired in a $25-\mu \mathrm{l}$ reaction volume containing $2.5 \mu \mathrm{l} 10 \times$ fragmentation buffer and $5 \mu \mathrm{l}$ fragmentation enzyme mix. The reaction was carried out at $4{ }^{\circ} \mathrm{C}$ for $1 \mathrm{~min}, 32{ }^{\circ} \mathrm{C}$ for $24 \mathrm{~min}$, and $65^{\circ} \mathrm{C}$ for $30 \mathrm{~min}$. Next, $10 \mu \mathrm{l} 5 \times$ ligation buffer, $5 \mu \mathrm{l}$ DNA ligase, and $2.8 \mu \mathrm{l} 25 \mu \mathrm{M}$ barcoded adapters were added along with enough water to reach a reaction volume of $50 \mu \mathrm{l}$. Reaction tubes were then incubated at $20^{\circ} \mathrm{C}$ for $15 \mathrm{~min}$. To ensure complete removal of free barcoded adapters, each reaction was purified using $1.4 \times($ or $1.0 \times)$ QIAseq beads for two rounds. The purified DNA was then mixed in a $20-\mu \mathrm{l}$ reaction volume with $10 \mathrm{nM}$ each target primer, $400 \mathrm{nM}$ IL-Forward primer, $1 \times \mathrm{TEPCR}$ buffer, and $0.8 \mu \mathrm{l}$ HotStarTaq DNA polymerase. The PCR protocol was as follows: $95^{\circ} \mathrm{C}$ for $13 \mathrm{~min} ; 98^{\circ} \mathrm{C}$ for $2 \mathrm{~min}$; six cycles of $98{ }^{\circ} \mathrm{C}$ for $15 \mathrm{~s}$ and $65{ }^{\circ} \mathrm{C}$ for $15 \mathrm{~min}$; and $72{ }^{\circ} \mathrm{C}$ for $5 \mathrm{~min}$. Each reaction was cleaned once using $1.4 \times($ or $1.0 \times$ ) QIAseq beads to remove unused primers. Enriched DNA was combined with $400 \mathrm{nM}$ IL-Index primers, $1 \times$ UPCR buffer, and $1 \mu$ l HotStarTaq DNA polymerase in a volume of $20 \mu \mathrm{l}$. The universal PCR conditions were as follows: $95^{\circ} \mathrm{C}$ for $13 \mathrm{~min} ; 98^{\circ} \mathrm{C}$ for $2 \mathrm{~min}$; 20 cycles of $98{ }^{\circ} \mathrm{C}$ for $15 \mathrm{~s}$ and $60^{\circ} \mathrm{C}$ for $2 \mathrm{~min}$; and $72{ }^{\circ} \mathrm{C}$ for $5 \mathrm{~min}$. The DNA library was purified once using $1.4 \times$ (or 1.0 $\times$ ) QIAseq beads and quantified using Qubit Fluorometric Quantitation (Thermon Fisher Scientific-US, Waltham, MA, USA). Libraries were sequenced on Illumina NextSeq (paired-end, $2 \times 150 \mathrm{bp}$ ) according to the manufacturer's instructions (Illumina, San Diego, CA, USA). TGS analysis was described in detail in our previous work [15].

\section{WES and data analysis}

A total of 50 ng DNA (based on Qubit quantification) was tagmented by a transposome, followed by clean-up and amplification of the tagmented DNA. A 200-400 bp band was selected, and exome capture was performed 
using the Nextera Exome Library Preparation Kit (Illumina). The DNA library was quantified using the Qubit 3.0 Fluorometer (Invitrogen) and Agilent 4200 Bioanalyzer (Agilent Technologies, Santa Clara, CA, USA). Samples were subjected to paired-end sequencing using the Illumina NovaSeq 6000 platform with a 150-bp read length. WES analysis has been described in detail in our previous work [16].

\section{RNA sequencing (RNA-seq)}

Total RNA was extracted from clinical tissue samples using the NucleoSpin ${ }^{\circledR}$ RNA Kit (MACHEREY-NAGEL GmgH, Düren, Germany) following the manufacturer's instructions. The quality, quantity, and integrity of the total RNA were evaluated using the NanoDrop1000 spectrophotometer and Bioanalyzer 2100 (Agilent Technologies). Samples with an RNA integrity number $>6.0$ were used for RNA-seq. An mRNA-focused, barcoded library was generated using the TruSeq strand mRNA Library Preparation Kit (Illumina). The libraries were sequenced on the Illumina Nova Seq 6000 instrument (Illumina), using $2 \times 151$-bp paired-end sequencing flow cells following the manufacturer's instructions.

\section{RNA-seq data analysis}

Illumina bcl2fastq Conversion Software (v2.20.0.422) was utilized to convert raw sequencing data to fastq format (Illumina). Trimmomatic PE (v0.39) was applied to control the read quality and remove sequencing adapters [17]. Reads were discarded if their average quality was $<20$ (AVGQUAL:20) and their read length $<105$ bp (MINLEN:105). Next, paired quality-controlled reads were aligned to the human genome (GRCh38), and gene expression was quantified using transcripts per million normalization via the HISAT2 (2.1.0) [18] and StringTie (1.3.5) [19] pipelines. To evaluate the similarities between different regions from the same tissue, we applied Spearman's rank correlation of the transcripts per million values of 299 gene signatures [20]. A heatmap of the gene expression values was plotted using Morpheus (https:// software.broadinstitute.org/morpheus), and the correlation coefficients were visualized using Seaborn, a Python data visualization library (https://github.com/mwaskom/ seaborn).

\section{Statistical analysis}

All statistical analyses were performed using SPSS software ver. 22.0. Chi-squared or Fisher's exact tests were used to compare two categorical variables. Survival analysis was performed using Kaplan-Meier survival plot and log-rank test. A p-value less than 0.05 was considered statistically significant.

\section{Results}

Patient characteristics

The patients in this study comprised 39 males and 33 females, with a mean age of 62.35 years, of whom 61 had ADC, 10 had SqCC, and 1 had combined ADC and SqCC. Stage I disease was identified in 38 patients, stage II in 12 patients, stage III in 10 patients, and stage IV in 6 patients (Table 1).

\section{Genomic alterations}

Among the 72 samples, 32 contained driver mutations in well-known cancer genes in NSCLC, such as EGFR $(\mathrm{n}=26$; E709G, T790M, L858R and non-frameshift deletions of exon 19), and PIK3CA $(\mathrm{n}=4$; E542K and G1049R). Besides EGFR and PIK3CA, other known mutations were detected in $K R A S(\mathrm{n}=4 ; \mathrm{G} 12 \mathrm{~V}, \mathrm{G} 12 \mathrm{~A}$, $\mathrm{G} 12 \mathrm{D}$, and $\mathrm{Q} 61 \mathrm{H})$, which have all been reported as driver mutations in lung cancer. In addition, four samples carried known activating mutations in the well-known oncogenes CTNNB1 $(\mathrm{n}=3$; S33F, S37C and S37F) and $\operatorname{MET}(\mathrm{n}=1 ; \mathrm{R} 1004 \mathrm{X}$ and c.3028+1G $>\mathrm{T})$. Overall, 34 specimens harbored driver mutations in five cancer genes (EGFR, PIK3CA, KRAS, CTNNB1, and MET), which are canonical driver mutations (Additional file 1: Table S1). These mutations were mutually exclusive, except for four cases of double mutations ( $\mathrm{n}=2$; EGFR and CTNNB1 and $\mathrm{n}=2 ; E F G R$ and PIK3CA). TP53 was the most frequently

Table 1 Description of Taiwanese NSCLC cases

\begin{tabular}{ll}
\hline Variable & $\begin{array}{l}\text { No } \\
\text { of patients } \\
\mathbf{N = 7 2}(\%)\end{array}$ \\
\hline Age (years) & \\
Mean \pm SD & $62.35 \pm 13.59$ \\
Range & $36-83$ \\
Gender & \\
Male & 39 \\
Female & 33 \\
Clinical stage & \\
I & $38(55.78)$ \\
II & $12(16.67)$ \\
III & $10(13.89)$ \\
IV & $6(8.33)$ \\
Missing & $6(8.33)$ \\
Histology type & \\
Adenocarcinoma & $61(84.72)$ \\
Squamous cell carcinoma & $10(13.89)$ \\
ADC+SqCC & $1(1.39)$ \\
Smoking status & \\
Non-smokers & $47(65.28)$ \\
Smokers & $25(34.72)$ \\
\hline
\end{tabular}


mutated gene after EGFR ( $\mathrm{n}=18$; S95fs, K120X, T125T, W146X, 152 153del, V173A, F212fs, G245C, G245D, R248L, R248W, R273H, R273C, V274D, E286K, and c.673-1G > T) (Additional file 1: Table S1). Among the 16 TP53 variants, two were novel (S95fs and F212fs).

\section{Comparisons between Taiwanese and Caucasian patients with NSCLC}

To compare the frequency of driver mutations of NSCLC between Taiwanese and Caucasian patients, we obtained all available lung cancer cases (560 ADC and $489 \mathrm{SqCC}$ ) from the TCGA dataset. Notable differences from the TCGA data included the frequencues of mutations in EGFR (36.11\% vs. 9.82\%, p<0.0001), KRAS (5.56\% vs. $15.92 \%, \mathrm{p}=0.0165)$, and TP53 (25.00\% vs. $69.69 \%, \mathrm{p}<0.0001)$. A full comparison of the frequencies

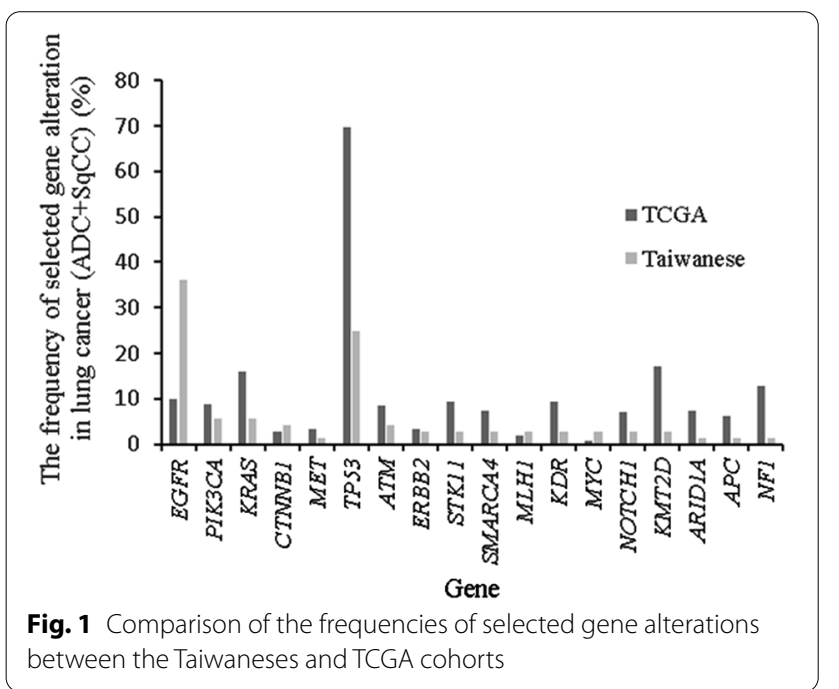

of selected gene alterations between the two cohorts is depicted in Fig. 1 and Additional file 1: Table S2.

\section{Clinically relevant genomic alterations}

Based on the latest NSCLC guidelines published by the National Comprehensive Cancer Network, clinically relevant genomic alterations were identified in 34 (47.22\%) patients (Table 2). As shown in Table 2, the clinically relevant alterations included in EGFR (26, 36.11\%), ERBB2 (2, 2.78\%), KRAS (4, 5.56\%), MET (1, 1.38\%), and NTRK1 (1, $1.38 \%)$.

Among the 26 patients with EGFR mutation patients, only 8 had an additional TP53 mutation, of whom 1 died of a cause unrelated to NSCLC. Among the 7 remaining patients, 3 had good survival outcomes, and 4 did not. We compared the genetic differences between the patients with a good and those with a poor survival outcome. In addition to the EGFR and TP53 mutations, one patient with poor survival harbored a $M Y C$ nonframeshift deletion (p.48_48del, rs776629119), and one patient with good survival had an $A R$ non-frameshift insertion (p.L57delinsLQQQ, rs4045402) and a FBXW7 non-frameshift deletion (p.117_117del, rs781154022), and another patient with good survival had a CTNNB1 (p.S37F, rs121913403) mutation.

\section{Correlations between driver mutations} and clinicopathological characteristics

Correlations between the genotypes and clinicopathological characteristics are listed in Table 3. The EGFR mutation rate was significantly higher in patients with ADC than in those with SqCC $(41.0 \%$ vs. $10.0 \%, \mathrm{p}=0.059)$. Moreover, the EGFR mutation rate was significantly higher in patients without smoking than in those with smoking (44.7\% vs. $20.0 \%, \mathrm{p}=0.038)$. No association was

Table 2 Genomic alterations associated with targeted therapies

\begin{tabular}{|c|c|c|c|}
\hline Gene & Alteration & Targeted therapy & Frequency \\
\hline Any gene (s) & & & 34 \\
\hline \multirow[t]{4}{*}{$E G F R$} & $L 858 R+E 709 G$ & Gefitinib & 1 \\
\hline & Exon 19 deletion & Erlotinib, Gefitinib, Afatinib & 12 \\
\hline & L858R + T790M & Osimertinib & 1 \\
\hline & L858R & Erlotinib, Gefitinib, Afatinib & 12 \\
\hline \multirow[t]{4}{*}{ KRAS } & G12V & Resistance to Erlotinib and Gefitinib & 1 \\
\hline & G12A & Resistance to Erlotinib and Gefitinib & 1 \\
\hline & G12D & Resistance to Erlotinib and Gefitinib & 1 \\
\hline & Q61H & Resistance to Erlotinib and Gefitinib & 1 \\
\hline ERBB2 & Insertion & Afatinib, Dacomitinib, Trastuzumab & 2 \\
\hline \multirow[t]{2}{*}{ MET } & $\mathrm{R} 1004 \mathrm{X}$ & Crizotinib & 1 \\
\hline & c. $1738+1 \mathrm{G}>\mathrm{T}$ & & \\
\hline NTRK1 & R646C & Entrectinib & 1 \\
\hline
\end{tabular}




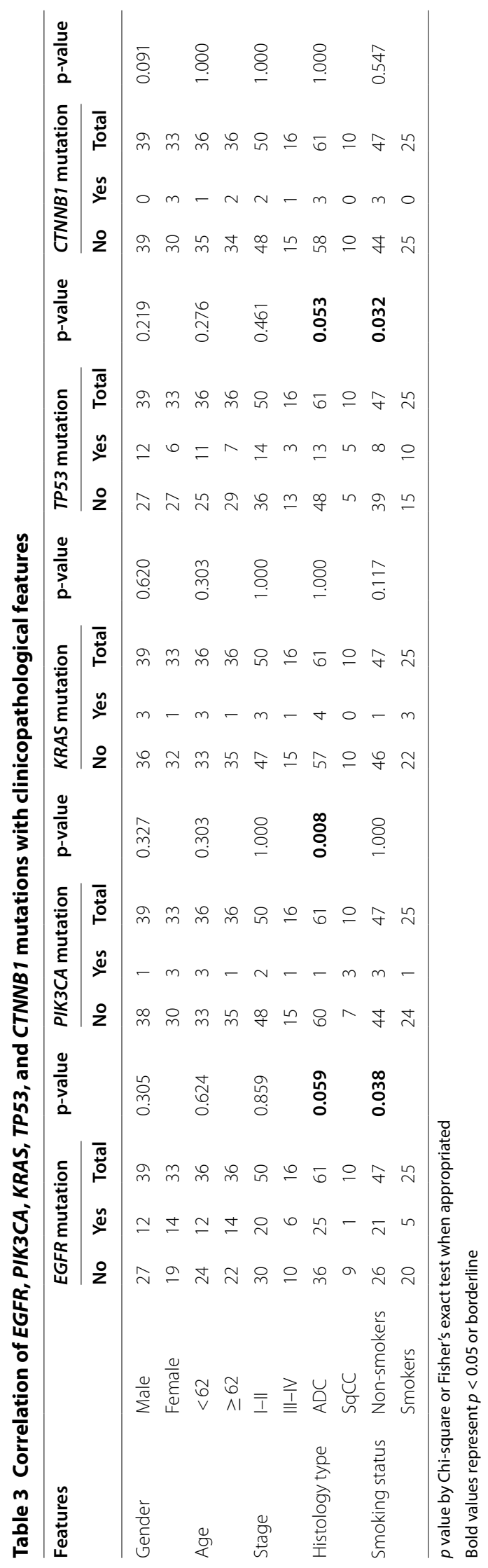


found between the EGFR mutation status and sex, age, or tumor stage of the patients. In contrast, the PIK3CA and TP53 mutation rates were significantly higher in patients with SqCC than in those with ADC (30.0\% vs. $1.6 \%, \mathrm{p}=0.008$ and $50.0 \%$ vs. $21.3 \%, \mathrm{p}=0.053$ ). Furthermore, the TP53 mutation rate was significantly higher in patients with smoking than in those without smoking (40.0\% vs. $17.0 \%, \mathrm{p}=0.032)$. No association was found between KRAS or CTNNB1 mutations and any clinicopathological characteristic.

We used Kaplan-Meier curve analysis to assess overall survival. In our cohort, PIK3CA mutation was a prognostic of worse overall survival (Fig. 2). There was, however, no significant difference in mortality between $E G F R$, KRAS, TP53, and CTNNB1 mutations (Additional file 2: Figure $\mathrm{S} 1$ ).

\section{Identification of trunk or branch driver mutations}

To exame intratumor heterogeneity, we applied multiregion WES in 8 tumor regions from 4 resected tissues (Fig. 3a). In order to determine whether driver genes carry trunk or branch mutations, we identified potential driver mutations among the 299 known cancer driver genes [20]. All variants classified as pathogenic in the ClinVar database are trunk mutations present in two tumor regions (Additional file 1: Table S3). Among the 61 predicted pathogenic variants identified from four patients $(15,11,16$, and 19 , respectively), 37 were classified as trunk mutations $(11,4,7$, and 15 , respectively) (Fig. 3b, Additional file 1: Table S4).

We further analyzed the variant allele frequencies of the trunk and branch mutations. Generally, the variant allele frequencies in four paired samples suggested that trunk mutations (median: $0.23-0.34 \%$ ) occurred much more frequently than branch mutations (median: 0.12$0.15 \%$ ) (Fig. 3c).

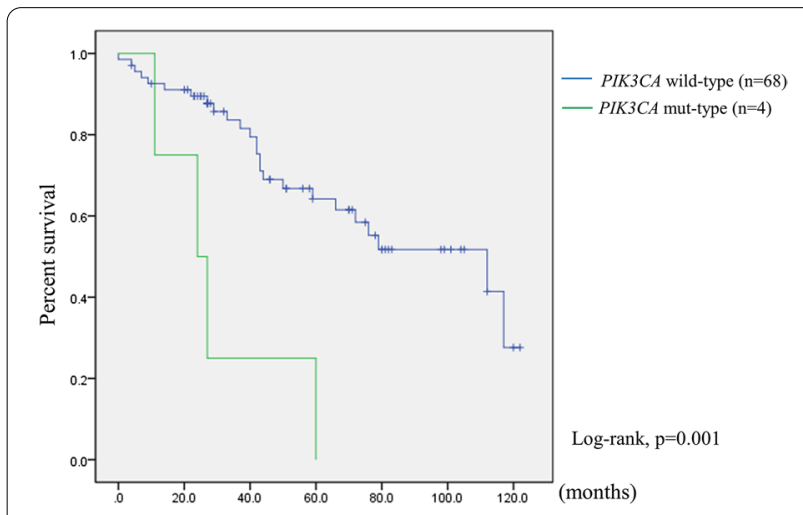

Fig. 2 Kaplan-Meier survival curve of patients with PIK3CA mutations
We also analyzed the expression of the driver genes that carried trunk or branch mutations. Gene expression profiles revealed no differences in driver genes harboring trunk or branch mutations between the two different tumor regions of the four paired samples (Fig. 3d).

\section{Intratumoral heterogeneity of $\mathbf{2 9 9}$ driver genes}

We determined the intratumoral expression of 299 driver genes, which were derived from 33 cancer types in the PanCancer dataset [20]. We used Spearman's rank correlation to calculate the gene expression correlations between two regions from four tumors each. Two regions from a tumor showed the highest correlation coefficient (Fig. 4).

The numbers of differentially expressed genes with a fold change in expression $>4$ in the four paired samples were 4 (FGFR2, PRKAR1A, MYC, and MYD88), 1 (MYD88), 4 (KMT2C, GNA11, ALB, and B2M), and 2 (KLF5 and $C D K N 2 A$ ), respectively (Additional file 1: Table S5). Most of the genes showed consistent expression (fold change $\leq 4$ ). There were few differences between the different regions within the same tumor, and we suggest that any differences were due to branch mutations. Thus, the 299-driver gene signature may correctly predict cancer etiology if assessed from a single tumor region.

\section{Discussion}

In the present study, we successfully performed comprehensive genomic profiling in tumor specimens from 72 Taiwanese NSCLC patients using WES or TGS. We found that EGFR mutations were more common in patients with $\mathrm{ADC}$, irrespective of sex, age, or tumor stage. PIK3CA and TP53 mutation rates were also higher in patients with SqCC. A comparison of driver gene mutations in our NSCLC patients with the TCGA dataset showed that EGFR was mutated at a much higher frequency in our Taiwanese cohort compared with Caucasians. In contrast, KRAS, BRAF, and TP53, the most common mutated genes in Caucasians, were found in only $5.56,0$, and $25 \%$, respectively, of the Taiwanese NSCLC patients in our study, which is consistent with other studies [12, 21]. These differences are most likely due to racial and environmental differences.

In addition, we also identified 83 novel variants in 72 genes. Eighteen of these have been reported as cancer driver genes (ARID1A, ARID2, CDK12, CHEK2, GNAS, H3F3A, KDM6A, KMT2C, NOTCH1, RB1, RBM10, RYNX1, SETD2, SF3B1, SMARCA4, THRAP3, TP53 and ZMYM2) (Additional file 1: Table S6) [20]. Eight driver genes were associated with LUAD and LUSC.

$A R I D 1 A$ encodes a member of the SWI/SNF family of proteins. Mutation of $A R I D 1 A$ has been documented in 


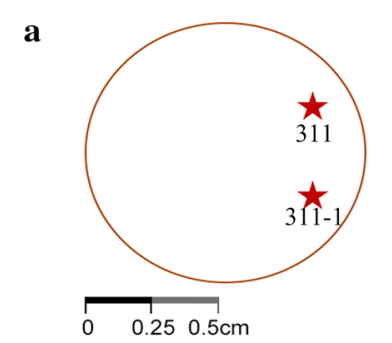

b

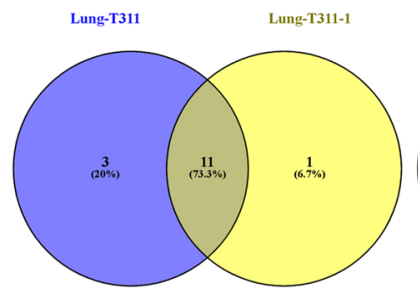

c
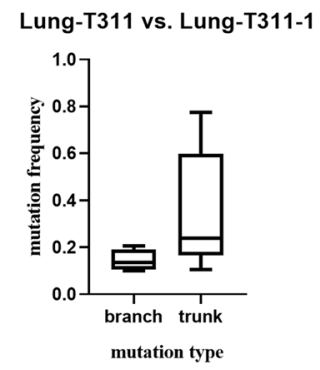

d

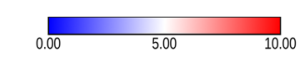

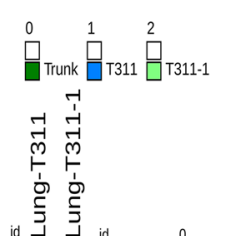

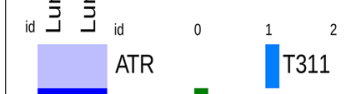

\begin{tabular}{ll|l}
\hline APOB & Trunk \\
\hline MSH3 & Trunk \\
\hline
\end{tabular}

KMT2C Trunk T311 T311-1

SOX17 Trunk

JAK2 Trunk

MUC6 Trunk T311

RBM10 Trunk

EGFR Trunk T311 T311-1
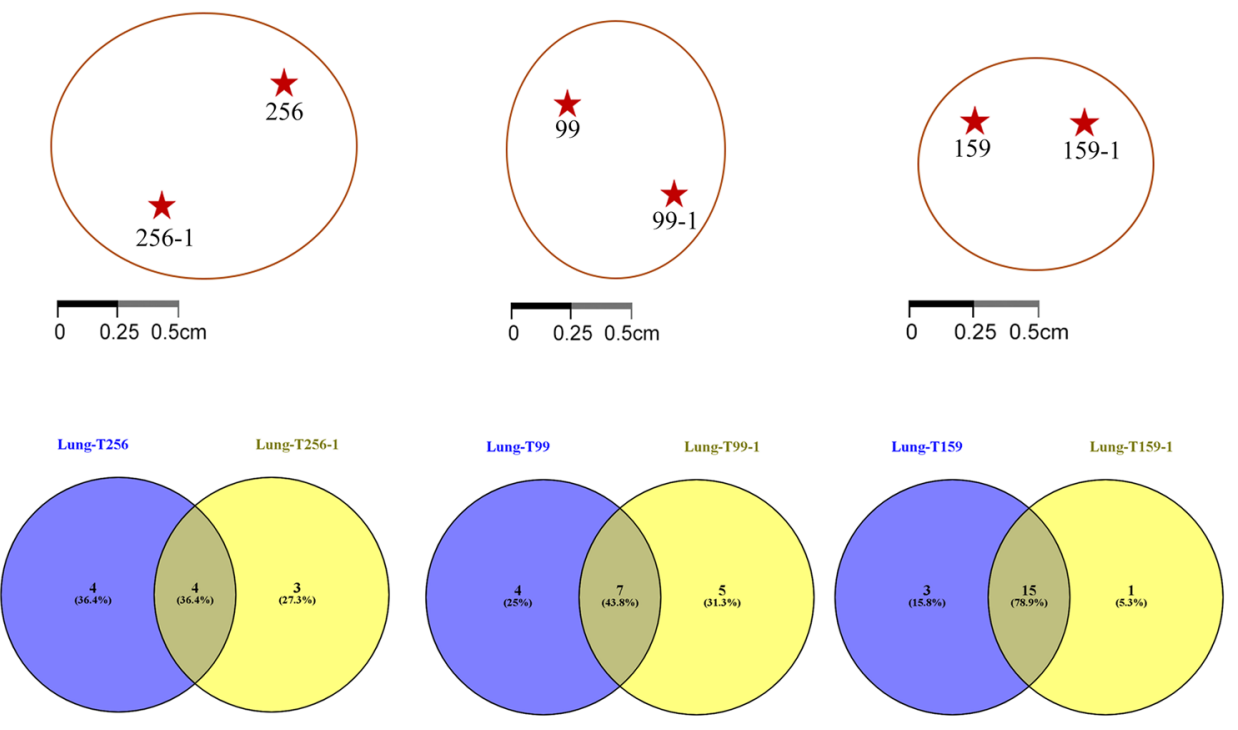

Lung-T99 vs. Lung-T99-1
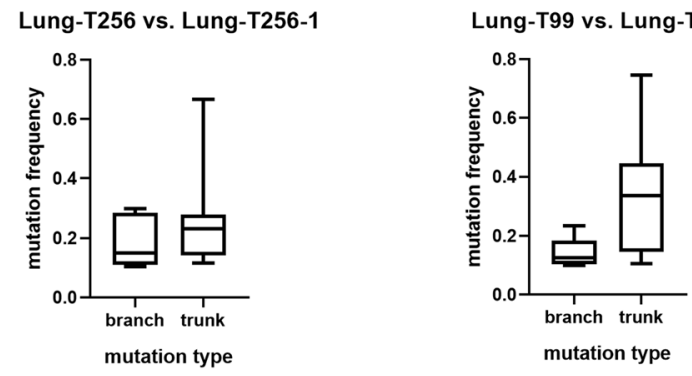

Lung-T159 vs. Lung-T159-1

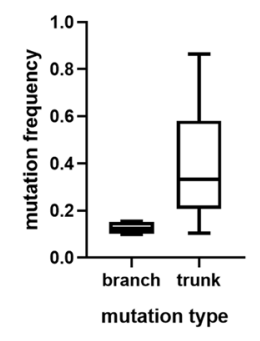

Fig. 3 Intratumoral genetic heterogeneity and homogeneity in four patients with NSCLC. a The regions harvested from the same surgically resected NSCLC. $\mathbf{b}$ Distribution of trunk and branch mutations in each region of the samples. $\mathbf{c}$ Mutation frequencies of trunk and branch mutations. d Gene expression analysis of the trunk and branch genes 


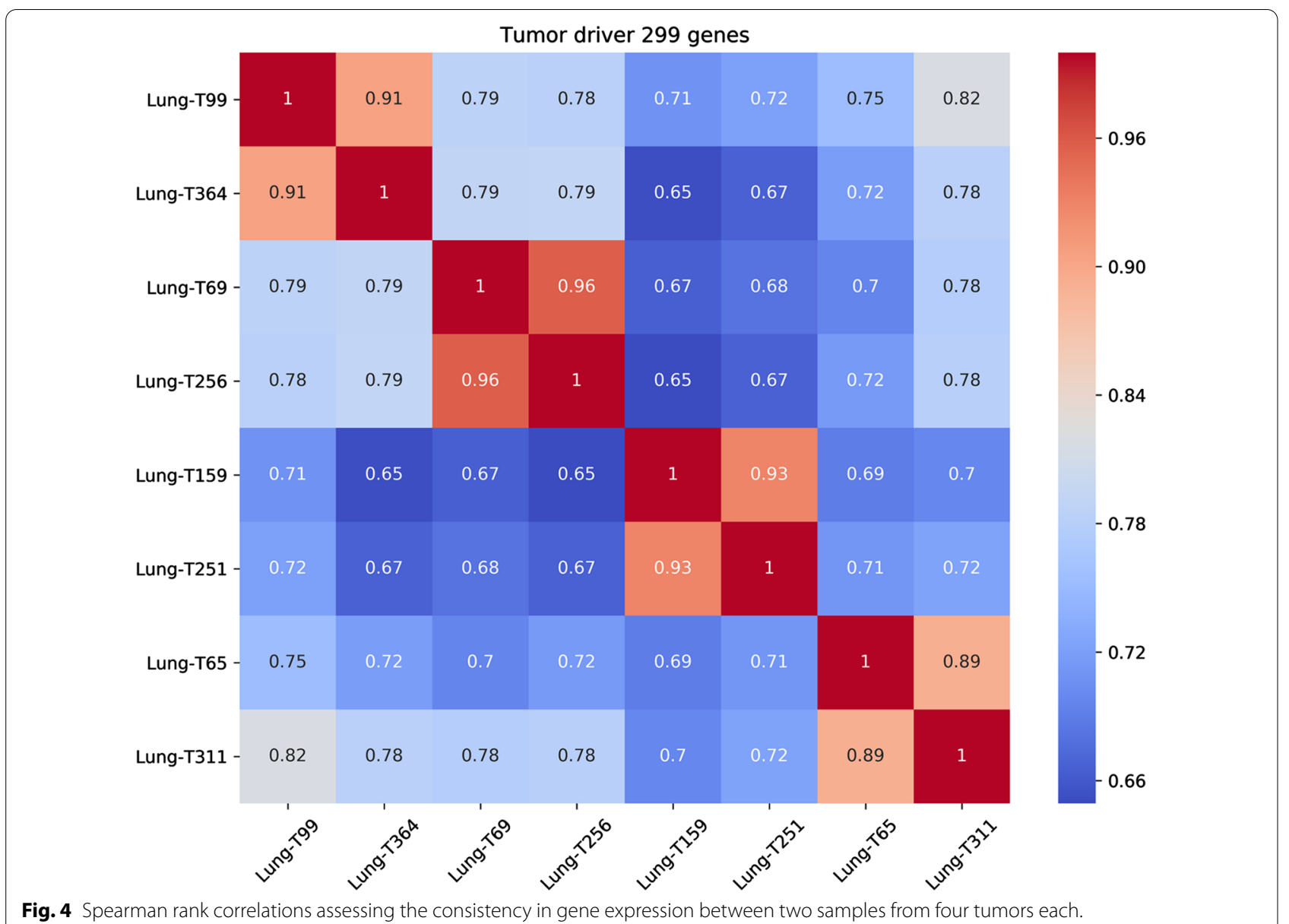

a number of cancers [22], and approximately $8 \%$ of lung ADCs contain mutations in ARID1A [23]. In this study, we identified a novel ARID1A mutation (p.G933fs) in a patient with $\mathrm{SqCC}$.

$K D M 6 A$ is located on chromosome $\mathrm{Xp} 11$ and encodes a tetratricopeptide repeat protein. The protein contains a Jumonji $\mathrm{C}$ domain and catalyzes the demethylation of tri/dimethylated histone H3. KDM6A is a tumor suppressor gene in different cancers, including lung SqCC [20]. In this study, we identified a novel KDM6A mutation (p.S314X) in a patient with SqCC.

NOTCH1, a member of the NOTCH protein family, contains an extracellular domain consisting of multiple epidermal growth factor-like repeats (36) and an intracellular domain consisting of multiple domain types. NOTCH1 is reported to have a bimodal role as a tumor suppressor and an oncogene in several cancers [24, 25]. In this study, we identified a novel NOTCH1 mutation (p.E2534K) in a patient with SqCC.

$R B 1$ encodes a negative regulator of the cell cycle protein and was the first tumor suppressor gene identified. Its tumor suppressive function is due to inhibition of the transcription factor E2F1. Any defect in the $R B 1$ gene causes cells to transition from the G1 to S-phase of the cell cycle [26]. RB1 is inactivated in a wide range of cancers, including lung ADC and SqCC. In this study, we identified a novel $R B 1$ mutation (p.I848fs) in a patient with ADC. The I848fs mutation occurs in the $C$ domain, which mediates the interaction with E4F1 [27].

$R B M 10$, a tumor suppressor gene $[28,29]$, encodes a nuclear protein that contains an RNA-recognition motif. RBM10 regulates pre-mRNA splicing in the alternative splicing pathway [30]. In this study, we identified a novel RBM10 mutation (p.A410fs) in a patient with ADC.

SETD2 encodes a protein that interacts with huntingtin. The protein is a histone methyltransferase responsible for the tri-methylation of lysine 36 on histone H3 (H3K36me3), using H3K36me2 as a substrate [31]. SETD2 is a tumor suppressor gene expressed in different cancer types [32]. In this study, we identified a novel SETD2 mutation (p.L1525P), present in the AWS domain, in a patient with $\mathrm{SqCC}$.

SMARCA4, also known as BRG1, encodes a member of the SWI/SNF family, which possesses helicase 
and ATPase activities. Human SWI/SNF enzyme subunits are mutated in approximately $20 \%$ of cancers [33]. SMARCA4 is possibly tumor supressive in lung ADC. In contrast, SMARCA4 may also be an oncogene in liver hepatocellular carcinoma, lower-grade glioma, and pan-cancer [20]. In this study, we identified a novel SMARCA4 mutation (p.Q570fs) in a patient with ADC.

Recently, Skoulidis et al. reported that co-occurring genomic alterations affect the response of NSCLC to anticancer therapies [34]. The mean overall survival was $82.30 \pm 9.80$ months for the EGFR mutant TP53 wildtype cohort, $86.88 \pm 15.41$ months for the EGFR/ TP53-mutant cohort; $\mathrm{p}=0.839$ (Additional file 2: Figure S2). Among them, 11 patients used EGFR-TKI therapy. We also assessed whether there are differences in survival after EGFR-TKI therapy. The mean overall survival was $58.29 \pm 10.26$ months for the EGFR mutant TP53 wildtype cohort $(\mathrm{n}=8), 114.50 \pm 2.50$ months for the EGFR/TP53-mutant cohort $(\mathrm{n}=3) ; \mathrm{p}=0.216$ (Additional file 2: Figure S3). The difference in survival time between these two group was not significant, which may due to small sample size. We also assessed the overall survival of patients with EGFR/TP53-mutant lung cancers. Our cohort contained eight patients with co-existing EGFR/TP53-alterations. We compared the mutational signatures between the patients with a good and those with a poor survival outcome. The presence of a co-existing $M Y C$ alteration was associated with worse survival in patients with EGFR/TP53-mutant lung ADCs. Moreover, a co-existing $A R, F B X W 7$, or $C T N N B 1$ alteration was associated with better survival in patients with EGFR/TP53-mutant lung ADCs. In our study, a relatively small number of patients with coexisting EGFR/TP53 alterations was identified.

Intratumoral heterogeneity presents a major challenge in precision cancer therapy because it can lead to underestimation of the tumor genomic landscape when based on single tumor biopsy samples, and this might contribute to drug resistance and treatment failure [35]. All known ClinVar pathogenic mutations were identified in all regions of individual tumors. The predicted pathogenic variants were trunk mutations, with a frequency ranging from 36.36 to $78.95 \%$. We found that the trunk or branch mutations were expressed at a constant level based on the transcriptome data. We found few genes with varying expression levels in different regions of the same sample, and our results differ slightly from those of other study [36], which may be because our selected regions were close in proximity.

In summary, we identified genomic aberrations underlying NSCLC in a Taiwanese population. Our study provides putative biomarkers for prognostic prediction in lung cancer. Further research is required to elucidate the functions of these genes and their pathways.

\section{Supplementary Information}

The online version contains supplementary material available at https://doi. org/10.1186/s12931-020-01608-5.

Additional file 1: Table S1. Mutations in five cancer genes in the 72 patients. Table S2. Comparison of driver gene mutations of lung cancer between Taiwanese patients and the Caucasian cohort in TCGA dataset. Table S3. List of trunk mutations of ClinVar pathogenic variants in four paired samples. Table S4. List of trunk and branch mutations of prediction pathogenic variants in four paired samples. Table S5. List of differentially expressed genes with a fold change in expression $>4$ in four paired samples. Table S6. Novel mutations in cancer driver genes.

Additional file 2: Figure S1. Kaplan-Meier survival curve of patients with EGFR, KRAS, TP53, and CTNNB1 mutations. Figure S2. Kaplan-Meier survival curve of 18 patients with EGFR mutation TP53 wild-type versus 8 patients with EGFR/TP53 mutations. Figure S3. Kaplan-Meier survival curve of 8 patients with EGFR mutation TP53 wild-type versus 3 patients with EGFR/TP53 mutations after EGFR-TKI treatment.

\section{Acknowledgements}

The data analyzed in this study were partially provided by the China Medical University Hospital Cancer Registry.

\section{Authors' contributions}

YSC and JGC conceived and designed the experiments and wrote the paper. SJT performed computation analyses. YCC and TYL analyzed the data. YTL and JCY performed experiments. HYF collected the specimen and performed clinical review. JGC contributed reagents and materials and interpretation of data. All authors read and approved the final manuscript.

\section{Funding}

This work was supported by China Medical University Hospital (DMR-109-109).

Ethics approval and consent to participate

The present study was approved by the Institutional Review Board of the China Medical University Hospital (CMUH106-REC1-053).

\section{Consent for publication}

Not applicable.

\section{Competing interests}

The authors declare that they have no competing interests.

\section{Author details}

${ }^{1}$ Epigenome Research Center, China Medical University Hospital, 2 Yuh-Der Road, Taichung 404, Taiwan. ${ }^{2}$ Department of Laboratory Medicine, China Medical University Hospital, Taichung, Taiwan. ${ }^{3}$ Center for Precision Medicine, China Medical University Hospital, Taichung, Taiwan. ${ }^{4}$ Department of Medical Laboratory Science and Biotechnology, China Medical University, Taichung, Taiwan. ${ }^{5}$ Department of Thoracic Surgery, China Medical University Hospital, Taichung, Taiwan. ${ }^{6}$ School of Medicine, China Medical University, Taichung, Taiwan. ${ }^{7}$ Department of Bioinformatics and Medical Engineering, Asia University, Taichung, Taiwan.

Received: 14 April 2020 Accepted: 20 December 2020

Published online: 06 January 2021

\section{References}

1. Ferlay J, Colombet M, Soerjomataram I, Mathers C, Parkin DM, Pineros M, Znaor A, Bray F. Estimating the global cancer incidence and mortality in 2018: GLOBOCAN sources and methods. Int J Cancer. 2019;144:1941-53. 
2. Siegel R, Ma J, Zou Z, Jemal A. Cancer statistics, 2014. CA Cancer J Clin. 2014;64:9-29.

3. Malhotra J, Malvezzi M, Negri E, La Vecchia C, Boffetta P. Risk factors for lung cancer worldwide. Eur Respir J. 2016;48:889-902.

4. Belani CP, Marts S, Schiller J, Socinski MA. Women and lung cancer: epidemiology, tumor biology, and emerging trends in clinical research. Lung Cancer. 2007;55:15-23.

5. Zhou F, Zhou C. Lung cancer in never smokers-the East Asian experience. Transl Lung Cancer Res. 2018:7:450-63.

6. Ha SY, Choi SJ, Cho JH, Choi HJ, Lee J, Jung K, Irwin D, Liu X, Lira ME, Mao $M$, et al. Lung cancer in never-smoker Asian females is driven by oncogenic mutations, most often involving EGFR. Oncotarget. 2015;6:5465-74.

7. Hirsch FR, Scagliotti GV, Mulshine JL, Kwon R, Curran WJ Jr, Wu YL, PazAres L. Lung cancer: current therapies and new targeted treatments. Lancet. 2017;389:299-311.

8. Kanodra NM, Silvestri GA, Tanner NT. Screening and early detection efforts in lung cancer. Cancer. 2015;121:1347-56.

9. Cancer Genome Atlas Research N. Comprehensive molecular profiling of lung adenocarcinoma. Nature. 2014;511:543-50.

10. Cancer Genome Atlas Research N. Comprehensive genomic characterization of squamous cell lung cancers. Nature. 2012;489:519-25.

11. Devarakonda S, Morgensztern D, Govindan R. Genomic alterations in lung adenocarcinoma. Lancet Oncol. 2015;16:e342-351.

12. Zhang XC, Wang J, Shao GG, Wang Q, Qu X, Wang B, Moy C, Fan Y, Albertyn Z, Huang $X$, et al. Comprehensive genomic and immunological characterization of Chinese non-small cell lung cancer patients. Nat Commun. 2019:10:1772.

13. Faruki H, Mayhew GM, Serody JS, Hayes DN, Perou CM, Lai-Goldman M. Lung adenocarcinoma and squamous cell carcinoma gene expression subtypes demonstrate significant differences in tumor immune landscape. J Thorac Oncol. 2017;12:943-53.

14. Friedlaender A, Banna G, Malapelle U, Pisapia P, Addeo A. Next generation sequencing and genetic alterations in squamous cell lung carcinoma: where are we today? Front Oncol. 2019;9:166.

15. Chang YS, Fang HY, Hung YC, Ke TW, Chang CM, Liu TY, Chen YC, Chao DS, Huang HY, Chang JG. Correlation of genomic alterations between tumor tissue and circulating tumor DNA by next-generation sequencing. J Cancer Res Clin Oncol. 2018;144:2167-75.

16. Chang CC, Chang YS, Huang HY, Yeh KT, Liu TC, Chang JG. Determination of the mutational landscape in Taiwanese patients with papillary thyroid cancer by whole-exome sequencing. Hum Pathol. 2018;78:151-8.

17. Bolger AM, Lohse M, Usadel B. Trimmomatic: a flexible trimmer for Illumina sequence data. Bioinformatics. 2014;30:2114-20.

18. Kim D, Paggi JM, Park C, Bennett C, Salzberg SL. Graph-based genome alignment and genotyping with HISAT2 and HISAT-genotype. Nat Biotechnol. 2019;37:907-15.

19. Pertea M, Pertea GM, Antonescu CM, Chang TC, Mendell JT, Salzberg SL. StringTie enables improved reconstruction of a transcriptome from RNAseq reads. Nat Biotechnol. 2015;33:290-5.

20. Bailey MH, Tokheim C, Porta-Pardo E, Sengupta S, Bertrand D, Weerasinghe A, Colaprico A, Wendl MC, Kim J, Reardon B, et al. Comprehensive characterization of cancer driver genes and mutations. Cell. 2018;173:371385 e318.
21. Liu L, Liu J, Shao D, Deng Q, Tang H, Liu Z, Chen X, Guo F, Lin Y, Mao M, et al. Comprehensive genomic profiling of lung cancer using a validated panel to explore therapeutic targets in East Asian patients. Cancer Sci. 2017;108:2487-94.

22. Takeda T, Banno K, Okawa R, Yanokura M, Iijima M, Irie-Kunitomi H, Nakamura K, lida M, Adachi M, Umene K, et al. ARID1A gene mutation in ovarian and endometrial cancers (review). Oncol Rep. 2016;35:607-13.

23. Imielinski M, Berger AH, Hammerman PS, Hernandez B, Pugh TJ, Hodis E, Cho J, Suh J, Capelletti M, Sivachenko A, et al. Mapping the hallmarks of lung adenocarcinoma with massively parallel sequencing. Cell. 2012;150:1107-20.

24. Westhoff B, Colaluca IN, D'Ario G, Donzelli M, Tosoni D, Volorio S, Pelosi G, Spaggiari L, Mazzarol G, Viale G, et al. Alterations of the Notch pathway in lung cancer. Proc Natl Acad Sci USA. 2009;106:22293-8.

25. Fukusumi T, Califano JA. The NOTCH pathway in head and neck squamous cell carcinoma. J Dent Res. 2018;97:645-53.

26. Burkhart DL, Sage J. Cellular mechanisms of tumour suppression by the retinoblastoma gene. Nat Rev Cancer. 2008;8:671-82.

27. Fajas L, Paul C, Zugasti O, Le Cam L, Polanowska J, Fabbrizio E, Medema $R$, Vignais ML, Sardet C. pRB binds to and modulates the transrepressing activity of the E1A-regulated transcription factor p120E4F. Proc Natl Acad Sci USA. 2000;97:7738-43.

28. Hernandez J, Bechara E, Schlesinger D, Delgado J, Serrano L, Valcarcel J. Tumor suppressor properties of the splicing regulatory factor RBM10. RNA Biol. 2016;13:466-72.

29. Ji Y, Xie S, Jiang L, Liu L, Li L, Luo L, Chen Y, Zhang J, Yu L, Zhang Y, et al. Increased cell apoptosis in human lung adenocarcinoma and in vivo tumor growth inhibition by RBM10, a tumor suppressor gene. Oncol Lett. 2017;14:4663-9.

30. Glisovic T, Bachorik JL, Yong J, Dreyfuss G. RNA-binding proteins and posttranscriptional gene regulation. FEBS Lett. 2008:582:1977-86.

31. Wagner EJ, Carpenter PB. Understanding the language of Lys36 methylation at histone H3. Nat Rev Mol Cell Biol. 2012;13:115-26.

32. Li J, Duns G, Westers H, Sijmons R, van den Berg A, Kok K. SETD2: an epigenetic modifier with tumor suppressor functionality. Oncotarget. 2016;7:50719-34

33. Wu Q, Lian JB, Stein JL, Stein GS, Nickerson JA, Imbalzano AN. The BRG1 ATPase of human SWI/SNF chromatin remodeling enzymes as a driver of cancer. Epigenomics. 2017;9:919-31.

34. Skoulidis F, Heymach JV. Co-occurring genomic alterations in non-smallcell lung cancer biology and therapy. Nat Rev Cancer. 2019;19:495-509.

35. McGranahan N, Swanton C. Biological and therapeutic impact of intratumor heterogeneity in cancer evolution. Cancer Cell. 2015;27:15-26.

36. Gerlinger M, Rowan AJ, Horswell S, Math M, Larkin J, Endesfelder D, Gronroos E, Martinez P, Matthews N, Stewart A, et al. Intratumor heterogeneity and branched evolution revealed by multiregion sequencing. $\mathrm{N}$ Engl J Med. 2012:366:883-92

\section{Publisher's Note}

Springer Nature remains neutral with regard to jurisdictional claims in published maps and institutional affiliations.

Ready to submit your research? Choose BMC and benefit from

- fast, convenient online submission

- thorough peer review by experienced researchers in your field

- rapid publication on acceptance

- support for research data, including large and complex data types

- gold Open Access which fosters wider collaboration and increased citations

- maximum visibility for your research: over 100M website views per year

At BMC, research is always in progress.

Learn more biomedcentral.com/submissions 